\title{
A trust to fight for desert wildlife in Namibia
}

From information supplied by Barry Clements, Blythe Loutit, Garth Owen-Smith and P.J. Viljoen.

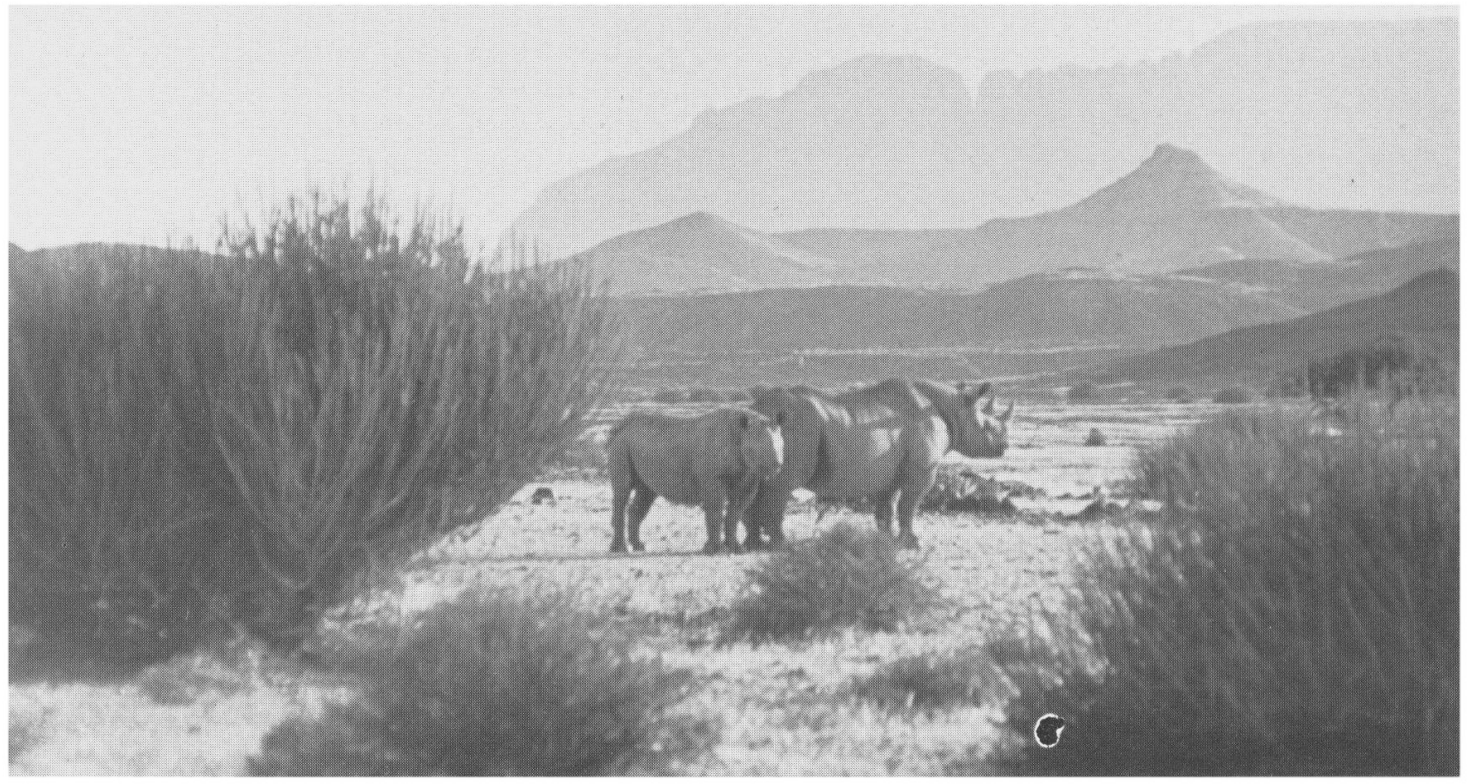

Cow and calf rhino in typical Damaraland habitat. The vegetation is Euphorbia damarana, endemic to this desert (B.D. Loutit)

The Namibia Wildlife Trust was set up in 1982, mainly in response to the slaughter by poachers of the elephants and rhinos of the desert in the northern part of the country. The Trust's efforts are meeting with some success but must be sustained if the large mammals of this unique area are to survive.

The Northern Namib, part of the oldest desert in the world, is a land where stark mountain ranges are intercepted by great sandy valleys and wide gravel plains. Situated in the north-west corner of Namibia, stretching from the Ugab River in the south to the Kunene River in the north, it encompasses five million hectares. Roads are few, narrow and rough. The rain, if it falls, is less then $150 \mathrm{~mm}$ per year.

Namibia Wildlife Trust
The desert is the habitat of large mammals such as elephant, giraffe, black rhinoceros, mountain zebra, cheetah and lion. In scientific terms, their adaptation make this desert one of the most interesting in the world. In economic terms, the tourist potential is unsurpassed-elephants crossing the dunes, giraffe on seemingly endless gravel plains without a tree in sight, rhinos climbing steep rocky mountainsides, and lions hunting seals on a barren beach. But in this unique and until recently unabused land, a note of dissonance has crept in.

In March 1983 a young female rhino was killed by poachers, leaving a four-month-old calf to die. It was saved, however, by a Namibia Wildlife Trust (NWT) patrol and is now in the care of the Department of Nature Conservation. The Trust was set up in April 1982 by conservationists concerned about the slaughter by poachers of large 


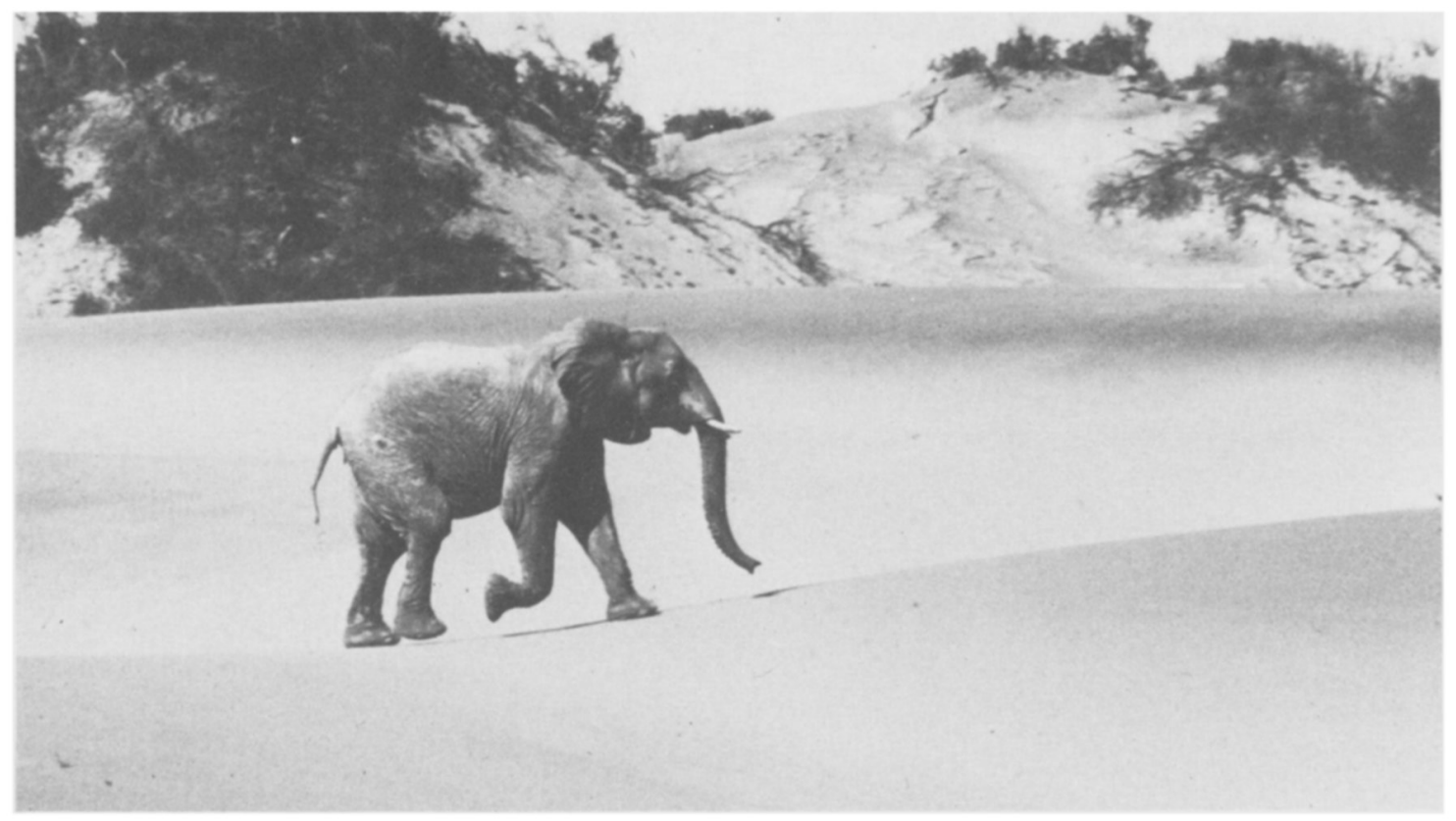

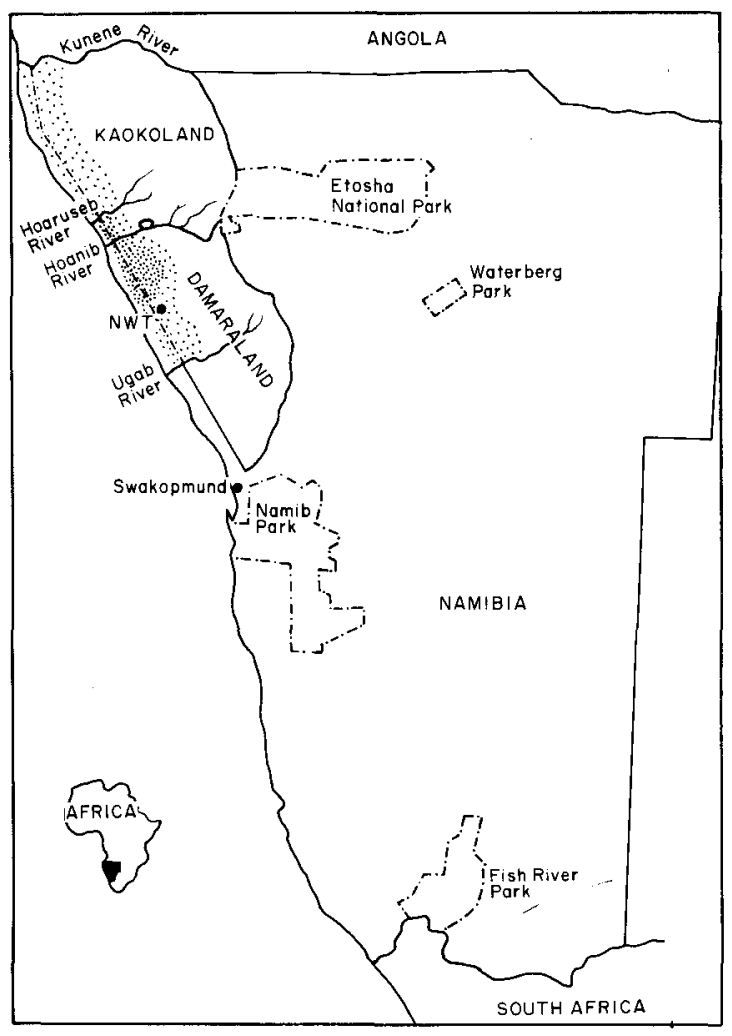

mammals in Kaokoland and Damaraland in areas outside the game reserves and parks. The Trust, with the support of the People's Trust for Endangered Species, the Endangered Wildlife Trust and the Wildlife Society of South West Africa, has begun a protection programme, particularly for elephant, black rhino and mountain zebra. The first priority is to protect elephant and black rhino in the desert east of Skeleton Coast Park. The Trust has provided anti-poaching units with four-wheel drive vehicles to co-operate with the Department of Nature Conservation in their patrols. At present there are two NWT staff doing this work, too few to cover the vast area effectively, but with more funds the Trust would be able to employ a full team of field-workers. A small aircraft, owned and flown by Martin Bertens and

\footnotetext{
Hobitot of desert elephont, rhino, giroffe ond zebro

-.-.- Gome Parks

Rivers: Kunene: perennial river

Hooruseb, Hoonib and Ugob hove linear ooses and are

dry most of the year, flowing only between Jonuory ond Moreh

NWT: Namibio Wildlife Trust heodquarters
} 
Left: One of the few remaining elephants, on the dunes in the Namib Desert (G. Owen-Smith).

Right: Typical vegetation (Euphorbia virosa) and habitat for rhino in Damaraland (B.D. Loutit).

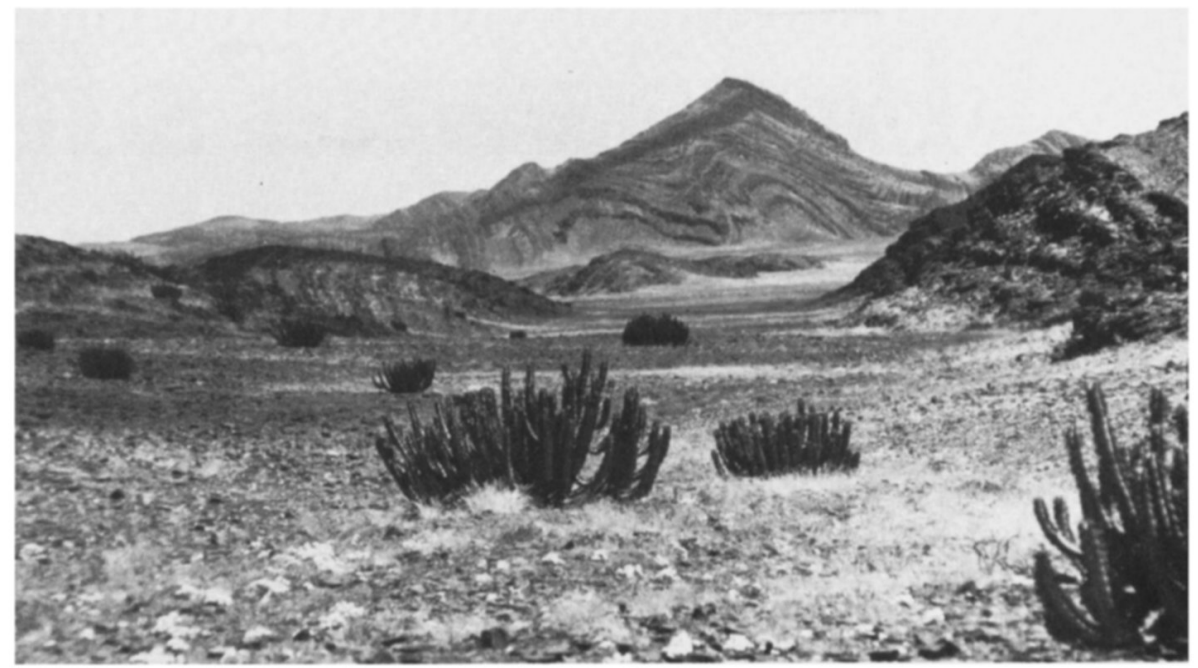

Hans Kriess, businessman from Swakopmund, is used to back up the ground patrol, the fuel being provided by Trust funds.

The decline in elephant and rhino numbers has indeed been severe. In 1970 elephants occurred throughout most of Kaokoland and Damaraland; $200-300$ of a total of $600-800$ occurred in the west. By 1977 only 250 were left, with about 65 in the west; in 1982 an aerial census, sponsored by the Trust, revealed that elephants survived in only three places in Kaokoland; six cows along the lower Kunene River; 18 cows, six sub-adult animals and six bulls in the lower HoanibHoaruseb area in the far south-west; five animals in south-east Kaokoland on the Ombonde River. In western Damaraland there are an estimated 30-36 left.

Numbers of black rhino have been drastically reduced in Kaokoland: none was seen in the aerial survey. Recent ground work, however, has revealed that they have survived in very small numbers and there is hope that, with better protection, they shall once more breed there. In Damaraland the rhino population has been extensively investigated by the NWT and it has been found that numbers are healthy and viable breeding groups are present in secluded areas where it has become difficult for would-be poachers to gain access without being detected by NWT patrols. A complete 'identikit' for each rhino observed has been drawn up, which records all identification features plus good close-

Namibia Wildlife Trust up photographs. Spoor (footprint) sizes are also recorded, which enable the NWT to identify which rhinos are using a particular waterhole. Elephants are also recorded and identified by photographs and family group size, but further equipment and staff are desperately needed.

It is claimed that if the elephants and rhinos are exterminated from this desert it would prove almost impossible to replace them with animals from other places since the knowledge of the whereabouts of hidden waterholes, which are sometimes as much as $70 \mathrm{~km}$ apart, is passed on from generation to generation. At a meeting in 1981 (see, Elephants and Rhinos in Africa: a Time for Decision, IUCN, 1982) the IUCN/SSC Elephant and Rhino Group recognised the importance of these remnant desert populations and expressed concern over their plight. The group decided that it was of the utmost priority to approach the authorities in Namibia with a view to bringing about a change in policy and securing the safety of the animals.

\section{Postscript}

The Damaraland and Kaokoland protection project has been taken over by the Endangered Wildlife Trust of South Africa. Mr Garth OwenSmith remains the Senior Field Officer in control and the Wildlife Society of South West Africa is assisting by raising funds for the continuation of the project. Their address is: Namib Centre of the Wildlife Society, PO Box 483, Swakopmund 9000 Namibia/SWA. 